\title{
Research on the Operating Efficiency of Listed Companies in the "National Quality Award" Based on the DEA-Tobit Model
}

\author{
Quanyu Zhang ${ }^{1}$, Xin Zhao ${ }^{2 *}$ \\ ${ }^{1}$ School of Management, Xi'an University of Science and Technology, Xi'an, Shaanxi 710054 \\ ${ }^{2}$ School of Management, Xi'an University of Science and Technology, Xi'an, Shaanxi 710054 \\ ${ }^{*}$ Corresponding author. Email: 799372954@qq.com
}

\begin{abstract}
The "National Quality Award" is an award won by domestic companies with excellent quality management. It is awarded to companies with excellent overall quality management models. Studying the management experience of these companies will help guide various companies to enhance their competitive advantages and cultivate their The core competitiveness of the global market is of great significance. This article uses DEA-BCC and Tobit models to study the listed companies that have won the "National Quality Award" from 2007 to 2019. Through qualitative and quantitative analysis, the result is the maturity of the total quality management system High companies have satisfactory technical efficiency; the total asset turnover rate and the proportion of R\&D personnel have a positive impact on corporate operating efficiency, and the significant fluctuations of personnel scale on economic efficiency. In this regard, it is recommended that companies should be Among the elements, the total asset scale, technology, people and other elements are positioned as the prominent core elements of the "National Quality Award" management model, and continuous investment and management are required to cultivate sustainable competitive advantages to achieve the goal of sustained success.
\end{abstract}

Keywords: National Quality Award, Operational Efficiency, DEA-Tobit Model

\section{INTRODUCTION}

More than 120 countries and regions have established quality management awards around the world, among which the American "Baldrige Quality Award", the Japanese "Deming Quality Award", and the "European Quality Award" are the most representative. My country's"National Quality Award" was established in 2001. It is an award awarded to organizations that have made outstanding achievements in the process of implementing excellent quality management. Relevant information shows that after nearly 20 years, companies striving for national quality awards, especially listed companies that have won quality awards, have significantly improved their operating results or have continued to ensure good performance, and the stock market index has continued to rise or ensure good stock value benefits. At the same time, the overall economic benefits of the company continue to maintain the leading level in the industry, the core competitiveness of the company is also continuously enhanced, the company has a high degree of recognition from its peers, the company has a certain position in the domestic and international markets, and the market share continues to increase. What is the operating efficiency of the award-winning listed companies? What are the main influencing factors? What are the related factors? What is the role of the core influencing factors? Such issues require in-depth research and discussion. Based on this, this article analyzes and studies the main factors affecting the management experience of these outstanding award-winning companies, and seeks the core influencing factors of management, and determines the management for the quality award companies. The key point is that this will help guide award-winning companies to improve their competitive advantages in a targeted manner and promote the improvement of comprehensive management.

This article adopts a qualitative change to a quantitative method, and takes the listed companies that have won the "National Quality Award" in 2007-2019 as the object. For the companies that have won the 
"National Quality Award", the main key factors affecting the quality management level are transformed into the ability to operate efficiency. To analyze the significance of the operating efficiency of the award-winning company, and finally determine the key factors such as the operating efficiency of the award-winning company, the level of the quality management system, and the relevance of operating performance for regression analysis.

Ren Tingyu and Wang Zongjun used grounded theory method and composite matrix method to measure the contribution of "Yangtze River Quality Award" to Hubei Province's enterprises and regional economic development to provide data support ${ }^{[1]}$. Huang Shunchun, Midsummer uses the propensity score matching method and uses the micro data of 1,631 listed manufacturing companies across the country in 2014 to study the impact of the government quality award system on the earnings per share of listed companies ${ }^{[2]}$. Zhang Zhiqiang, Shangguan Shan Bin, and Wang Wei used propensity score matching method to conduct empirical analysis on 347 listed companies from 7 different industries, and studied the impact and extent of the national quality award on the overall industry operating performance ${ }^{[3]}$. Although many scholars have conducted research on the "National Quality Award", most of them are based on a certain province, city or region, and most of them use the score matching method. The corresponding results are obtained by comparing the operating conditions of the award-winning and non-awarded companies. The selected data The time span is relatively short. Only the award-winning units in a certain area have been studied. The research scope is not large enough and the quality award research cannot be more comprehensive. Therefore, this paper selects the listed companies that won the "National Quality Award" in 2007-2019, and uses the DEA-Tobit model to study the operating efficiency of the companies.

At this stage, various scholars have gradually matured the use of the DEA-Tobit model. Zhang Yulan and others believe that investment efficiency and technological innovation are key factors for the transformation and upgrading of manufacturing enterprises. They used the DEA model to invest in 158 listed manufacturing companies in Beijing, Tianjin and Hebei from 2016 to 2018 . The efficiency is evaluated ${ }^{[4]}$. Lai Mulan, Xu Na used the data envelopment analysis (DEA) method to evaluate the technological innovation efficiency of my country's pharmaceutical manufacturing industry, and analyzed the technological innovation efficiency ${ }^{[5]}$. Li Qingxue and Yu Jinchuang based on the analysis of the mechanism of technological policy on the servicization of my country's equipment manufacturing industry, combined with the panel data of the equipment manufacturing industry from 2011 to 2018, and used the DEA-Tobit method to measure the efficiency of my country's equipment manufacturing servicing technology policy, Empirical research on the factors affecting the efficiency of service-oriented technology policies ${ }^{[6]}$. These studies have calculated the efficiency value of the corresponding industry through the DEA-Tobit model, and then analyzed the key factors affecting the efficiency value. Through reading the relevant literature, combined with the development of Chinese enterprises, domestic scholars have rarely used the DEA model to study the operating efficiency of listed companies that have won the "National Quality Award". In view of this, this article adopts the DEA-Tobit method combined with listed companies Based on the relevant indicators of operating performance, obtain the operating efficiency value of each enterprise, analyze the key factors affecting operating efficiency, and give relevant suggestions for other types of enterprises to enhance their competitiveness.

\section{MODEL CONSTRUCTION AND INDEX SELECTION}

\subsection{Model interpretation}

\subsubsection{DEA analysis}

DEA (Data Envelopment Analysis) is data envelopment analysis, which was proposed by Charnes, Cooper and Rhodes in $1978^{[7]}$. It is mainly for multiple input and multiple output indicators. When it is difficult to measure the weight relationship between them with the help of price parameters, the DEA method can better evaluate the evaluation objects. In this paper, the DEA-BCC model assumes variable returns to scale (VRS) and decomposes technical efficiency into pure technical efficiency (PTE) and scale efficiency (SE). Technical efficiency is the product of the two, namely TE $=$ PTE*SE. This article selects the BCC model based on research needs. When pure technical efficiency and scale efficiency are not 1 , the smaller of the two indicators is the main factor affecting the overall efficiency. The specific linear model can be expressed as:

$$
\left\{\begin{array}{c}
\min \left[\theta-\varepsilon\left(\mathbf{s}^{+}+\mathbf{s}^{-}\right)\right] \\
\text {s.t. } \sum_{j=1}^{n} \lambda_{j} x_{j}+\boldsymbol{s}^{-}=\theta x_{0} \\
\sum_{j=1}^{n} \lambda_{j} y_{j}-s^{+}=y_{0} \\
\sum_{j=1}^{n} \lambda_{j}=1 \quad j=1,2, \cdots, n \\
s^{+} \geq 0, s^{-} \geq 0
\end{array}\right.
$$

\subsubsection{Tobit regression analysis}

When using the least squares method for regression analysis, the data of the variables are required to be continuous without boundaries, and when the data is a truncated value, it is easy to affect the results, and it is 
easy to cause bias and inconsistencies in the parameter estimates, so the least squares method It is no longer available for regression. In response to this problem, in 1958, the famous American economist Tobin proposed a Tobit analysis method in which the variable is a truncated value ${ }^{[8]}$. The expression of the model is as follows:

$$
\left\{\begin{array}{c}
Y_{i}^{*}=\chi_{i} \beta+\mu_{i} \\
Y_{i}=0, Y_{i}^{*} \leq 0 \\
Y_{i}=Y_{i}^{*}, Y_{i}^{*} \geq 0
\end{array}\right.
$$

Among them, $Y_{\mathrm{i}}^{*}$ is the latent variable, $\mathrm{x}_{\mathrm{i}}$ is the independent variable, $Y_{i}$ is the observation variable, $\beta$ is the coefficient of the regression model, and $\mu_{\mathrm{i}}$ is the error term.

The DEA and Tobit are combined to form the DEA-Tobit two-step method, which is widely used by scholars to evaluate and analyze various efficiency and influencing factors of the economic system. This article will use this method to evaluate the operating efficiency of my country's listed companies that have won quality awards, and further analyze its influencing factors, and provide certain suggestions for the development of other companies.

\subsection{Indicator selection and data sources}

\subsubsection{DEA-BCC indicator selection and data sources}

Based on the selection of input-output indicators by relevant scholars ${ }^{[9]}$, combined with the awarding characteristics of the quality award, this paper finally constructs 6 indicators, taking operating costs, total operating expenses, fixed assets, and management expenses as input indicators. Regarding total operating income and total profit as output indicators, the input-output indicators are shown in table 1. Combined with the time selection characteristics of the research objects in this article, the relevant indicators of corporate listing, such as net assets per share, earnings per share, and stocks are not adopted. Other indicators such as earnings.

Table 1. Input-output index table

\begin{tabular}{c|c|c}
\hline $\begin{array}{c}\text { Index } \\
\text { classification }\end{array}$ & Specific indicators & unit \\
\hline \multirow{4}{*}{ Investment index } & Operating cost & yuan \\
\cline { 2 - 3 } & Total operating expenses & yuan \\
\cline { 2 - 3 } & Fixed assets & yuan \\
\cline { 2 - 3 } & Management fees & yuan \\
\hline \multirow{2}{*}{ Output indicators } & Total operating income & yuan \\
\cline { 2 - 3 } & Total profit & yuan \\
\hline
\end{tabular}

This article mainly selects the data of Chinese listed companies that have won the "National Quality Award" from 2007 to 2019. The winning units are from the official website of the National Quality Award, and only the units that have won the quality award are considered. The specific units are shown in table 2 below. Each company The indicator data of is derived from the Wind database. For the data missing before 2008, in order to ensure the correctness of the model, this article only considers the award-winning listed companies after 2007. Because the data missing of Liugong Machinery

and People's Electrical Appliances is relatively large and the linear interpolation method cannot be used, this article does not consider it. These two companies. In addition, because the individual indicator data for measuring input-output efficiency has negative values, and the DEA model requires that the software input value cannot be negative, according to the principle of linear change invariance, the negative values of the indicator data are uniformly adjusted to positive values to meet The data requirements of the DEA model and ensure the smooth output of the software. Since the year in which each company received the quality award is selected, currency appreciation is not considered.

Table 2. Award-winning companies

\begin{tabular}{c|c|c|c|c|c}
\hline Award-winning company & $\begin{array}{c}\text { Number of } \\
\text { awards }\end{array}$ & $\begin{array}{c}\text { Award } \\
\text { year }\end{array}$ & Award-winning company & Number of awards & Award year \\
\hline Beixin Building Materials & 1 & 2019 & Xugong Machinery & 1 & 2014 \\
\hline Desay SV & 1 & 2019 & Liugon Machinery & 2 & $2014 、 2008$ \\
\hline Kweichow Moutai & 1 & 2019 & Rutai & 1 & 2013 \\
\hline Goldwind Technology & 1 & 2019 & Dunan Environment & 1 & 2012 \\
\hline
\end{tabular}




\begin{tabular}{|c|c|c|c|c|c|}
\hline Old white dry wine & 1 & 2019 & Tongling Nonferrous & 1 & 2012 \\
\hline Su Yanjing God & 1 & 2019 & Yanzhou Coal Industry & 1 & 2011 \\
\hline Zhaojin Mining & 1 & 2019 & Wuliangye & 2 & $2011 、 2003$ \\
\hline Zhongtian Technology & 1 & 2019 & Anyang Iron and Steel & 1 & 2011 \\
\hline YOFC Optical Fiber Cable & 1 & 2017 & Aokang International & 1 & 2011 \\
\hline Oriental Yuhong & 1 & 2017 & Angang Steel & 1 & 2010 \\
\hline Boss Electric & 1 & 2017 & JAC & 1 & 2010 \\
\hline Jinshiyuan & 1 & 2017 & Pearl River Piano & 1 & 2009 \\
\hline Shentong Metro & 1 & 2017 & Shaangu Power & 1 & 2009 \\
\hline Maanshan Iron and Steel & 1 & 2016 & Ocean King & 1 & 2009 \\
\hline Baotou Steel & 1 & 2015 & Bosideng & 1 & 2008 \\
\hline Don Ejiao & 1 & 2015 & People's Electric & 1 & 2008 \\
\hline Taigang Stainless & 1 & 2015 & Weichai Power & 1 & 2007 \\
\hline
\end{tabular}

In order to ensure the accuracy of the data in the paper, this paper selects the listed companies that have won the "National Quality Award" from 2007 to 2019 as the research object. The following table shows the descriptive statistical results of the industry input and output indicators as shown in table 3 , in the input and output indicators of the company. The average value of the company's net profit is about 1.06 billion, the maximum is about 41.2 billion, and the minimum is about 3.7 billion. This shows that among the companies that have won quality awards, some companies are even losing money. The difference in some indicators is more obvious. This also shows that the economic performance of the enterprises that have won the quality award also has some problems, and there is still a lot of room for improvement.

Table 3. Descriptive statistics of input and output of industry indicators

\begin{tabular}{c|c|c|c|c}
\hline Industry indicators & Mean & Minimum & Max & Standard deviation \\
\hline Operating cost & 17269244757 & 291901810 & 85409000000 & 21953625712 \\
\hline Total operating expenses & 19560319345 & 694576544 & 88876000000 & 22767969303 \\
\hline Fixed assets & 10868612273 & 42481000 & 57267000000 & 15727246705 \\
\hline Management fees & 988065422 & 17995405 & 6167982844 & 1144652245 \\
\hline Total operating income & 22824949577 & 749308817 & 91941000000 & 25098984864 \\
\hline Net profit & 1067330422 & -3711397609 & 41206471014 & 7303270288 \\
\hline
\end{tabular}

\subsubsection{Tobit indicator selection and data sources}

There are many factors influencing the economic performance of a company. Based on the research of many scholars ${ }^{[10]}$, the selection is mainly from the following aspects: The first level is to select the number of employees in the company from the economic level, which can better reflect the company the scale of the status quo. The second level is to select the development level of the city where each company is located from the geographic location, and the third level is to select the total operating income (year-on-year growth rate) from the corporate management level to reflect, and select the total asset turnover rate to reflect the company's operational capabilities. The variable description is shown in table 4 below:

Table 4. List of factors affecting corporate efficiency

\begin{tabular}{c|c|c|c}
\hline Level & name & variable & meaning \\
\hline Economic level & Number of employees & $\mathrm{YG}_{\mathrm{ij}}$ & Reflect the status quo of enterprise scale \\
\hline Location & City level & $\mathrm{CS}_{\mathrm{ij}}$ & City classification \\
\hline
\end{tabular}




\begin{tabular}{c|c|c}
\hline & Total operating income & $\mathrm{YY}_{\mathrm{ij}}$ \\
& Total asset turnover & $\mathrm{ZC}_{\mathrm{ij}}$ \\
Business & Proportion of Masters & $\mathrm{SS}_{\mathrm{ij}}$ \\
perspective & Proportion of R\&D personnel & $\mathrm{YF}_{\mathrm{ij}}$ \\
& Assets and liabilities & $\mathrm{FZ}_{\mathrm{ij}}$ \\
& & \\
\hline
\end{tabular}

The model constructed based on the above variables is as follows:

$$
y=c+\beta_{1} L n Y G_{i j}+\beta_{2} L n C S_{i j}+\beta_{3} Y Y_{i j}+\beta_{4} Z C_{i j}+\beta_{5} S S_{i j}+\beta_{6} Y F_{i j}+\beta_{7} F Z_{i j}+\varepsilon_{i j}
$$

In the formula, $y$ is the overall efficiency value of each enterprise, $c$ is a constant term, $\beta_{1}, \beta_{2}, \beta_{3}, \beta_{4}, \beta_{5}, \beta_{6}$, and $\beta_{7}$ are regression coefficients, which are residual items, and $\mathrm{i}$ represents each enterprise $\mathrm{i}=1,2,3 \ldots 32, \mathrm{j}$ represents the year, the specific value is 2007-2019, in order to ensure the accuracy and persuasiveness of the model, the number of employees is calculated with e as the base, and the city level data is logarithmic to eliminate and reduce the mutual influence between the data.

\section{EMPIRICAL ANALYSIS}

\subsection{DEA-BBC model index analysis}

The comprehensive technical efficiency (TE), pure technical efficiency (PTE) and scale efficiency (SE) of listed companies that have won the national quality award using DEAP2.1 in 2007-2919 are shown in table 5 below. The list of listed companies that have won the national quality award in 2007-2019. The average comprehensive technical efficiency value is 0.738 , the average pure technical efficiency value is 0.796 , the average scale efficiency value is 0.935 , and the pure technical efficiency is less than the average scale efficiency value, indicating that the average comprehensive technical efficiency value of each enterprise is affected by pure technical efficiency. This result is consistent the characteristics of most enterprises in our country, the scale efficiency of each enterprise meets certain requirements. It also reflects that the construction of the quality system has a certain role in promoting the overall technical efficiency of the enterprise.

Table 5. 2007-2019 operating efficiency value of each enterprise

\begin{tabular}{c|c|c|c|c} 
Company Name & TE & PTE & SE & Return to scale \\
\hline Zhongtian Technology & 0.931 & 0.931 & 1.000 & irs \\
\hline Zhaojin Mining & 0.413 & 0.432 & 0.955 & irs \\
\hline Su Yanjing God & 0.485 & 0.556 & 0.871 & irs \\
\hline Old white dry wine & 0.625 & 0.703 & 0.890 & irs \\
\hline Kweichow Moutai & 1.000 & 1.000 & 1.000 & - \\
\hline Beixin Building Materials & 0.669 & 0.682 & 0.981 & irs \\
\hline Desay SV & 1.000 & 1.000 & 1.000 & irs \\
\hline Goldwind Technology & 0.562 & 0.565 & 0.995 & irs \\
\hline JofC Optical Fiber Cable & 0.669 & 0.670 & 0.998 & irs \\
\hline
\end{tabular}




\begin{tabular}{|c|c|c|c|c|}
\hline Maanshan Iron and Steel Co., Ltd. & 0.625 & 0.625 & 0.999 & - \\
\hline Don Ejiao & 0.799 & 0.858 & 0.931 & irs \\
\hline Taigang Stainless & 0.609 & 0.747 & 0.815 & drs \\
\hline Baotou Steel & 0.532 & 0.536 & 0.992 & irs \\
\hline Xugong Machinery & 0.586 & 0.595 & 0.984 & irs \\
\hline Rutai A & 0.539 & 0.576 & 0.935 & irs \\
\hline Dunan Environment & 0.722 & 0.735 & 0.982 & irs \\
\hline Tongling Nonferrous & 1.000 & 1.000 & 1.000 & - \\
\hline Yanzhou Coal Industry & 1.000 & 1.000 & 1.000 & - \\
\hline Wuliangye & 0.688 & 0.694 & 0.991 & irs \\
\hline Anyang Iron and Steel & 0.743 & 0.750 & 0.991 & irs \\
\hline Aokang International & 0.974 & 1.000 & 0.974 & irs \\
\hline Angang Steel & 0.687 & 1.000 & 0.687 & drs \\
\hline JAC & 0.784 & 0.784 & 0.997 & irs \\
\hline Pearl River Piano & 0.533 & 1.000 & 0.533 & irs \\
\hline Shaangu Power & 0.601 & 0.649 & 0.926 & irs \\
\hline Ocean King & 1.000 & 1.000 & 1.000 & - \\
\hline Bosideng & 1.000 & 1.000 & 1.000 & - \\
\hline Weichai Power & 0.805 & 0.806 & 0.999 & drs \\
\hline Mean & 0.738 & 0.796 & 0.935 & \\
\hline
\end{tabular}

Most of the listed companies that have won quality awards tend to be at the same level of scale and efficiency, which also proves that the companies that have won national quality awards are representative. Combining the relationship between comprehensive technical efficiency, pure technical efficiency and scale efficiency, as well as the analysis of pure technical efficiency restricting the development of enterprises, enterprises should pay attention to technological innovation and improve technological internal power.

In order to study the average efficiency of listed companies that have received quality awards, the different efficiency interval tables are made as shown in
Table 6 below. The companies with technical efficiency of 0.6-0.7 are the most, pure technical efficiency and scale efficiency are roughly the same, and the number of companies is gradually increasing. The efficiency value of most companies is still considerable, but some companies still have a lot of room for improvement in input and output efficiency. This shows that the company has won the highest honor of "National Quality Award". Some companies have higher efficiency values. The efficiency value of the enterprise is low. The analysis shows that in the process of constructing and pursuing quality construction, enterprises should reasonably invest in related expenses, save costs, and obtain higher economic benefits.

Table 6. Comprehensive technical efficiency table

\begin{tabular}{c|c|c|c|c|c|c|c}
\hline technical efficiency & $0.4-0.5$ & $0.5-0.6$ & $0.6-0.7$ & $0.7-0.8$ & $0.8-0.9$ & $0.9-1$ & 1 \\
\hline Number of companies & 2 & 5 & 10 & 5 & 1 & 3 & 6 \\
\hline Percentage (\%) & 6.25 & 15.625 & 31.25 & 15.625 & 3.125 & 9.37 & 18.75 \\
\hline
\end{tabular}




\subsection{Tobit regression}

DEA can analyze the overall efficiency of the enterprise according to the input-output data, but cannot explain the key factors that affect the overall efficiency of the enterprise. Therefore, the tobit model is used to analyze the key factors. This article uses stata software to analyze the selected 7 variables. Perform Tobit regression analysis, and the results are shown in Table 7 below. The specific analysis is as follows:

It can be seen from the analysis results that first, the regression coefficient of the number of personnel on the operating efficiency of the company is $-0.077(\mathrm{P}<0.05)$. There is significant fluctuation. It can be seen that the greater the number of employees in an enterprise, the greater the economic efficiency of the enterprise cannot be brought about. The larger the size of the company in terms of number of people, it cannot bring corresponding advantages to the company. For example, the increase in economic benefits. The company should establish a personnel reward and elimination mechanism suitable for itself, and appropriately control the number of people, so as to improve its own economic benefits. .

Second, the regression coefficient of the total asset turnover rate on the business efficiency is $0.179(\mathrm{P}<0.01)$ and the significance is positively correlated. The total asset turnover rate factor stands out in the model, and the significance level is more obvious. This is the leader of the business. In terms of operation, it provides direction, speeds up the operation of assets, improves sales capabilities, and increases the speed of operation of input and output, which brings a significant increase in the economic benefits of the enterprise.

Third, the regression coefficient of the proportion of the number of R\&D personnel on the company's operating efficiency is $1.238(\mathrm{P}<0.01)$, and there is a significant positive correlation, which shows that the proportion of R\&D personnel can help companies have good operating efficiency, which also explains that talent is The internal driving force of technological innovation. Compared with the proportion of masters, the proportion of R\&D personnel is more significant. Therefore, companies should focus on the proportion of $\mathrm{R} \& \mathrm{D}$ personnel in production and operation activities and in the adjustment of talent structure. The proportion of employees should not be blindly pursued. It should be viewed rationally.

Table 7. Regression results of Tobit model

\begin{tabular}{c|c|c}
\hline VARIABLES & \multicolumn{2}{|c}{$\mathrm{y}$} \\
\hline YG $_{\mathrm{ij}}$ & $-0.077^{* *}$ & $(-2.25)$ \\
\hline $\mathrm{ZC}_{\mathrm{ij}}$ & $0.179^{* * *}$ & $(2.95)$ \\
\hline $\mathrm{CS}_{\mathrm{ij}}$ & -0.121 & $(-0.86)$ \\
\hline $\mathrm{YY}_{\mathrm{ij}}$ & -0.059 & $(-0.74)$ \\
\hline
\end{tabular}

\begin{tabular}{c|c|c}
\hline $\mathrm{SS}_{\mathrm{ij}}$ & 0.001 & $(0.09)$ \\
\hline $\mathrm{YF}_{\mathrm{ij}}$ & $1.238^{* * *}$ & $(4.31)$ \\
\hline $\mathrm{FZ}_{\mathrm{ij}}$ & 0.072 & $(0.42)$ \\
\hline sigma_u & 0.000 & $(0.00)$ \\
\hline sigma_e & $0.118^{* * *}$ & $(6.76)$ \\
\hline Constant & $1.475^{* * *}$ & $(4.32)$ \\
\hline Observations & 27 & \\
\hline Number of code & 7 & \\
\hline
\end{tabular}

Z-statistics in parentheses

$* * * \mathrm{p}<0.01, * * \mathrm{p}<0.05, * \mathrm{p}<0.1$

\section{CONCLUSION}

The main issues studied in this paper are the quality system, economic performance and factors affecting economic performance. Taking 32 listed companies that have won the "National Quality Award" as the research object, selecting the relevant data of each company that won the "National Quality Award" in the same year, using the DEA model to transform the management ability of the company into operating efficiency, although the companies selected in this article are all It is an award-winning company, but comparing the operating efficiency of various companies, there is still a big gap, which shows that the company has passed the quality management system certification and the company with a high level of comprehensive quality management system maturity has satisfactory technical efficiency.

After the research in this article, while the company is vigorously building a quality management system, it should not be superficial or just a response under the system. Managers should use the quality management system flexibly and transform the quality management system into business performance. In order to keep the quality management system running. Combined with the results of the $\mathrm{BCC}$ model, when an enterprise has a certain scale of efficiency while operating a quality management system, it should also improve pure technical efficiency at the same time, and there should be no pure technical efficiency restricting the technical efficiency of the enterprise.

After using the Tobit model to analyze related factors and indicators, the number of personnel, the turnover rate of total assets, and the number of R\&D personnel have a significant effect on the operating efficiency of the company. The number of personnel and the operating efficiency of the company are significant. This result has a significant impact on the size of the company. Development has a certain enlightenment. Only by establishing a certain incentive mechanism for personnel and controlling the scale of personnel can the operating efficiency of the enterprise be better improved. Compare the four factors of total operating income 
(year-on-year growth rate), city level, proportion of masters, and asset-liability ratio.

\section{REFERENCES}

[1] Ren Tingyu, Wang Zongjun. The contribution of "Yangtze River Quality Award" to corporate value and regional economy and policy recommendations[J]. Finance and Accounting Monthly, 2016(21): 76-79.

[2] Huang Shunchun, Sheng Xia. Is the government quality award system effective?-A study on the earnings per share of listed manufacturing companies based on the PSM method[J]. Friends of Accounting, 2016(14): 49-53.

[3] Zhang Zhiqiang, Shangguan Shan Bin, Wang Wei. Government Quality Award and Enterprise Operation Performance-Based on the Choice Data of the National Quality Award Winning Companies from 2001 to 2016[J]. Finance and Accounting Newsletter, 2018(26): 25-29+129 .

[4] Zhang Yulan, Jing Siting, Niu Shuang, Qiang Chunxia,Xuan Jie. Research on the Evaluation of Investment Efficiency of Beijing-Tianjin-Hebei Manufacturing Listed Companies_-Based on the Perspective of Technological Innovation[J]. Friends of Accounting, 2020(18): 14 -19.

[5] Lai Mulan, Xu Na, Ge Fulian, Wang Chengcheng, $\mathrm{Xu}$ Wen. Research on the Technology Innovation Efficiency of my country's Pharmaceutical Manufacturing Industry from 2007 to 2016 Based on the Data Envelopment Analysis Model[J]. Medical Herald, 2020, 39(11):1576 -1587.

[6] Li Qingxue, Qi Liangqun, Yu Jinchuang. Research on the efficiency of equipment manufacturing servicing technology policy and its influencing factors: an empirical analysis based on DEA-Tobit[J]. Business Research, 2020(07): 46-53.

[7] Charnes A.,Cooper W.W.,Rhodes E.. Measuring the efficiency of decision making units $[\mathrm{J}]$. Charnes A.;Cooper W.W.;Rhodes E., 1978,2(6).

[8] Estimation of Relationships for Limited Dependent Variables[J]. Econometrica,1958,26(1).

[9] Liu Huiming, Wu Su, Liu Ying. Research on the Operational Capability and Economic Performance of my country's Manufacturing Enterprises [J]. Industrial Engineering and Management, 2019, 24(04): 7-13.

[10] Chu Yanchang, Shen Yang, Lian Wenhao. Research on the efficiency of Chinese logistics enterprises based on DEA-Malmquist and Tobit models: empirical evidence from listed companies[J]. Mathematical Practice and Understanding, 2020, 50(10): $95-105$. 